\title{
The Nutritional Requirements of Methicillin-dependent and -resistant Strains of Pediococcus cerevisiae
}

\author{
By D. WIDDOWSON* AND P. J. WHITE \\ Department of Microbiology, The University, Western Bank, Sheffield Sio 2 TN
}

(Received 6 June 1975; revised I7 July 1975)

\section{SUMMARY}

A new methicillin-dependent and -resistant substrain (called MRD) of Pediococcus cerevisiae was developed by serial passage followed by replica-plating. Other methicillin-resistant, but not -dependent, substrains were isolated after treatment of the same parent strain with a mutagen. A methicillin-independent partial revertant, still resistant to the drug, was isolated from the original methicillin-dependent and -resistant substrain (CRD) developed several years ago.

The requirements of some of these strains for acetate, vitamins and amino acids were compared. All except the parent methicillin-sensitive strain required pantothenate for growth, but no other consistent differences were found. The parent, but not strain CRD, grew without lysine added to the medium, though 19 other amino acids were needed by each strain. Both of these strains fermented glucose to lactate (mainly the L-isomer) in the absence or presence of methicillin.

\section{INTRODUCTION}

A substrain of Pediococcus cerevisiae ATCC808I that was dependent on methicillin for growth in a chemically partly defined medium was isolated by White (1968 a). This substrain (called $P$. cerevisiae CRD) was 40 times more resistant to methicillin than the parent strain, but showed little increased resistance to benzyl penicillin. There were other differences between strain CRD and the parent in their nutritional requirements for tetrahydropteroylglutamate and acetate.

To determine whether any of these differences were directly attributable to methicillin dependence, a new methicillin-dependent resistant strain, a partial revertant (i.e. no longer methicillin-dependent, but still resistant) strain of CRD, and new methicillin-resistant but not dependent strains were isolated for comparative purposes. This second isolation of a methicillin-dependent strain suggested that the production of such strains is not the result of a very rare genetic event.

Markov \& Saev (1956) reported that with some benzyl penicillin-resistant strains of Staphylococcus aureus (the parent strain of which required thiamin and nicotinic acid), the growth-promoting effect of thiamin could be reproduced by benzyl penicillin at very low concentrations. An intact $\beta$-lactam ring was not necessary; penicilloic acid gave a similar effect. A substance was postulated to arise from benzyl penicillin that acted in a similar manner to thiamin (Markov \& Saev, 1957). Although these experiments were not entirely convincing, they prompted a comparison of the vitamin requirements of $P$. cerevisiae 808I and the various substrains. The amino acid requirements of the parent and CRD strains, and

\footnotetext{
* Present address: Department of Physiology and Biochemistry, University of Southampton, Southampton, $\mathrm{SO}_{9} \mathrm{5NH}$.
} 
the abilities of these two strains to ferment glucose in the presence and absence of methicillin were also studied.

A preliminary account of part of this work has been given (Widdowson \& White, 197I).

\section{METHODS}

Organisms. Pediococcus cerevisiae ATCC808I and CRD (the original methicillin-dependent substrain) were maintained as described previously (White, 1968a). The isolation of other substrains is described below.

Media. The partly defined medium (containing leucovorin, the calcium salt of 5-formyl tetrahydropteroylglutamate) was that described by White \& Nichol (1963) and will be referred to as medium SD. Peptone+yeast extract + glucose medium (PYG) and PYG + acetate (PYGAc) were as described by Wilkinson \& White (1973), except that a salts solution ( $10 \mathrm{ml} / \mathrm{l}$ ) was added; this contained (in $500 \mathrm{ml}$ of solution in distilled water): $\mathrm{MgSO}_{4} \cdot 7 \mathrm{H}_{2} \mathrm{O}, 20 \mathrm{~g} ; \mathrm{MnSO}_{4} \cdot 4 \mathrm{H}_{2} \mathrm{O}, 2 \mathrm{~g} ; \mathrm{FeSO}_{4} \cdot 7 \mathrm{H}_{2} \mathrm{O}$, I g; $\mathrm{NaCl}$, I g; concentrated (I $.6 \mathrm{M}$ ) HCl, $0.5 \mathrm{ml}$. Media were autoclaved at $12 \mathrm{I}{ }^{\circ} \mathrm{C}$ for $15 \mathrm{~min}$. Solutions of methicillin and benzyl penicillin were Seitz filtered and added to the cooled, sterile media.

To grow surface colonies of these microaerophilic organisms, sodium thioglycollate $(375 \mu \mathrm{g} / \mathrm{ml})$ was added to media, which also contained $\mathrm{I} \%(\mathrm{w} / \mathrm{v})$ agar. Solutions of sodium thioglycollate were sterilized by Seitz-filtering, and mixed into autoclaved medium at $44^{\circ} \mathrm{C}$.

Assessment of growth. All plates and liquid cultures (in stationary flasks or tubes) were incubated at $37^{\circ} \mathrm{C}$ and turbidities were measured in an EEL photoelectric colorimeter as described by White (1968a).

Isolation of new methicillin-dependent and -resistant strains. (i) Methicillin-dependent resistant strain. Pediococcus cerevisiae 808I was passaged in the presence of methicillin as described by White (I968a). After 3I transfers the culture was tested for the presence of organisms unable to grow without methicillin by plating on to medium SD containing methicillin $(50 \mu \mathrm{g} / \mathrm{ml})$, and then replicating (Lederberg \& Lederberg, 1952) the resulting colonies (after incubation for 2 days) on to media with and without methicillin. Colonies that grew only in the presence of the drug were picked for further testing.

(ii) Methicillin-independent revertant strains from CRD. Large inocula (0.1 ml of washed, exponential-phase organisms, equivalent to 0.3 to $0.03 \mathrm{mg}$ dry $\mathrm{wt} / \mathrm{ml}$ ) were plated on to medium SD without methicillin. Any large colonies that grew within 50 to $60 \mathrm{~h}$ were picked off and tested for growth without methicillin on fresh plates.

(iii) Methicillin-resistant strains. Washed, exponential-phase parent organisms (equivalent to about 0.5 to $0.7 \mathrm{mg}$ dry wt/ml) were incubated at $37^{\circ} \mathrm{C}$ for $30 \mathrm{~min}$ in $0.1 \mathrm{M}$-tris maleate buffer, $\mathrm{pH} 6 \cdot 0$, containing the mutagen $N$-methyl- $N^{\prime}$-nitro- $N$-nitrosoguanidine (NTG; $100 \mu \mathrm{g} / \mathrm{ml}$ ). The organisms were then washed twice in sterile water and inoculated into liquid PYG medium to allow expression of possible mutations. Medium SD $(20 \mathrm{ml})$, containing methicillin at various concentrations, was inoculated at $44^{\circ} \mathrm{C}$ with $\mathrm{I} \mathrm{ml}$ PYG culture and then poured into a plate and allowed to set. A $10 \mathrm{ml}$ overlay of the same uninoculated medium was added to provide conditions for microaerophilic growth (White, 1968a). This procedure was used before additions of thioglycollate had been introduced. Colonies of possible methicillin-resistant organisms were picked out with a straight wire and retested by stabbing into fresh methicillin-containing plates.

(iv) Methicillin-sensitive but -dependent strains. Exponential-phase parent organisms were treated with NTG as before, and the washed organisms were incubated in medium 
SD for $8 \mathrm{~h}$ at $37^{\circ} \mathrm{C}$ to allow growth of methicillin-independent bacteria. Sterile D-cycloserine was then added to a final concentration of $I \mathrm{mg} / \mathrm{ml}$ and incubation was continued for a further $18 \mathrm{~h}$. The organisms were washed twice and an inoculum equivalent to $0.5 \mathrm{mg}$ dry wt was used to inoculate $10 \mathrm{ml}$ of medium SD containing methicillin $(5 \mu \mathrm{g} / \mathrm{ml})$, which was then incubated overnight. After a further two cycles of treatment with cycloserine, the organisms were washed twice, diluted and tested for methicillin dependence by replicaplating on to medium SD with and without methicillin $(5 \mu \mathrm{g} / \mathrm{ml})$.

Determination of sensitivities to penicillins. Organisms were grown into exponential phase in PYG medium, washed twice and $0.1 \mathrm{ml}$ of a suspension (equivalent to about $3 \mu \mathrm{g}$ dry $\mathrm{wt} / \mathrm{ml}$ of water) was used to inoculate $2.4 \mathrm{ml}$ of medium SD in each of a series of $19 \times 150 \mathrm{~mm}$ test tubes containing either methicillin (o to $600 \mu \mathrm{g} / \mathrm{ml}$, in steps of $25 \mu \mathrm{g} / \mathrm{ml}$ ) or benzyl penicillin (0 to $5.0 \mu \mathrm{g} / \mathrm{ml}$, in steps of $0.5 \mu \mathrm{g} / \mathrm{ml}$ ). After incubation for 3 days the resistance of the organism was taken to be the highest concentration of the antibiotic which permitted growth.

Vitamin requirements. Exponential-phase organisms (grown in medium SD, containing $50 \mu \mathrm{g}$ methicillin $/ \mathrm{ml}$ where necessary) were washed once in sterile water. Samples of the washed bacteria (equivalent to $0.6 \mu \mathrm{g}$ dry $\mathrm{wt} / \mathrm{ml}$ ) were used to inoculate a series of $19 \times$ $150 \mathrm{~mm}$ tubes of medium SD ( $5 \mathrm{ml}$ final volume) from which single vitamins were omitted. Medium was prepared without vitamins and sterilized by Seitz-filtering. Vitamins were added (to the same final concentration as in the complete medium) as separate solutions that had been sterilized by filtration.

Amino acid requirements. Medium SD was prepared without the amino acids plus acidhydrolysed casein usually added. These were replaced by the mixture of amino acids used in the fully defined medium of Sauberlich \& Baumann (1948). To allow the amino acid content to be varied, each amino acid was made up in concentrated solution so that the addition of $0.1 \mathrm{ml}$ of each gave the final concentration required in $5 \mathrm{ml}$ of medium. In a series of $19 \times 150 \mathrm{~mm}$ tubes each amino acid was omitted in turn from the complete mixture which supported growth of $P$. cerevisiae $808 \mathrm{I}$. Methicillin $(50 \mu \mathrm{g} / \mathrm{ml})$ was added to medium for strain CRD. Tubes were inoculated as in the study of vitamin requirements.

Fermentation of glucose. Strains 808I and CRD were grown for $48 \mathrm{~h}$ (into stationary phase) in PYGAc and PYGAc + methicillin ( $100 \mu \mathrm{g} / \mathrm{ml}$ ), respectively, in 21 flasks containing $400 \mathrm{ml}$ medium. Each flask was inoculated with $\mathrm{I} \mathrm{ml}$ of the appropriate overnight culture in medium SD (plus methicillin for CRD). The bacteria were harvested by centrifuging, washed twice in $0.9 \% \mathrm{NaCl}$ and resuspended in water to about $30 \mathrm{mg}$ dry wt $/ \mathrm{ml}$. Each suspension $(0.5 \mathrm{ml})$ was incubated at $37^{\circ} \mathrm{C}$ in Warburg flasks containing sodium bicarbonate solution (20 $\mu \mathrm{mol}$ in $2.5 \mathrm{ml}$ total volume after all additions) under $5 \%(\mathrm{v} / \mathrm{v}) \mathrm{CO}_{2}$ in $\mathrm{N}_{2}$. After tipping in glucose $(5 \mu \mathrm{mol})$ the evolution of gas was followed manometrically (Umbreit, Burris \& Stauffer, 1964). Acid was tipped from a second side arm when the first gas evolution was over. The flask contents were assayed for glucose with glucose oxidase (Bergmeyer \& Bernt, 1965), for total lactate (Barker, 1957) and for L-lactate (Hohorst, 1965). The experiment was repeated for both strains with methicillin (100 $\mu \mathrm{g} / \mathrm{ml}$ ) in the Warburg flasks, and again repeated with phosphate buffer pH $6.5\left(20 \mu \mathrm{mol} / 2.5 \mathrm{ml}\right.$, replacing bicarbonate) under $\mathrm{N}_{2}$.

Chemicals. Lipoic acid was a gift from Dr J. R. Guest (University of Sheffield). Other chemicals were commercially available (and of analytical reagent purity where possible), or their origins were given by White (1968a) 
RESULTS

\section{Production of a new methicillin-dependent strain}

After 31 passages with methicillin, the resistance of $P$. cerevisiae to the antibiotic was increased about 50-fold. Cultures grew in medium without methicillin as quickly as in medium containing it until passage 20 , when, after incubation for $17 \mathrm{~h}$, the tubes containing $100 \mu \mathrm{g}$ methicillin/ml showed distinct growth whereas there was only faint turbidity in drugfree medium; after incubation for a further $23 \mathrm{~h}$, however, growth had become of equal density in both tubes. During the following I I passages differences in the growth of the cultures plus and minus methicillin were not consistent. Growth in medium without drug was slower in passages $23,24,26$ and 30 . These inconsistencies might have been due to the presence in the culture of a mixture of methicillin-dependent and -independent organisms, the latter being revertants to independence or organisms that had never become dependent.

Methicillin-dependent organisms were isolated after passage $3 \mathrm{I}$ by replica-plating. No replication was attempted during the earlier passages. Sodium thioglycollate in the solid medium enabled colonies to grow on the surface of plates, and did not inhibit the rate of growth or decrease the number of colonies formed in comparison with colonies grown by the uninoculated-overlay technique (White, 1968a). Methicillin-dependent organisms were present in the culture from passage $3 \mathrm{I}$ in a proportion of about I colony in 20. After suspected methicillin-dependent colonies had been tested on solid medium SD with and without methicillin $(50 \mu \mathrm{g} / \mathrm{ml})$, a methicillin-dependent colony was selected and designated as strain MRD (methicillin-resistant-dependent).

Cultures of strain MRD in liquid medium SD became turbid as rapidly in the absence of drug as in its presence, which suggested a high rate of reversion to drug independence. Organisms were plated onto medium plus and minus methicillin, and colonies that had grown after 3 days were counted. Approximately I colony in 15 grew in the absence of methicillin. This suggests that the revertants might grow faster in the absence of the drug than MRD did in its presence.

\section{Methicillin-resistant strains}

Strain 8081 Met $^{\mathrm{Ra}}$ was produced by NTG treatment of strain $808 \mathrm{I}$. It was inhibited by concentrations of methicillin higher than $75 \mu \mathrm{g} / \mathrm{ml}$. Strain Met $^{\mathrm{Ra}}$ was subjected to a further cycle of NTG treatment, and a strain (called met $^{\mathrm{Rb}}$ ) was isolated which could grow in the presence of $150 \mu \mathrm{g}$ methicillin/ml. Another strain ( $\mathrm{Met}^{\mathrm{Rb} 2}$ ) was obtained from a spontaneous mutation of met $^{\mathrm{ta}}$ by plating a large inoculum onto medium SD containing $150 \mu \mathrm{g}$ methicillin $/ \mathrm{ml}$ and selecting a single colony which grew.

Revertants of strain CRD to methicillin independence occur at a frequency of $I$ in $10^{5}$ (White, I968a). A revertant colony was picked from drug-free medium SD, and was called strain $\mathrm{CR}$ since it retained methicillin resistance (see below).

\section{Methicillin-sensitive yet-dependent organisms}

No success was achieved in six attempts (see Methods) to isolate organisms of this class. Such organisms would have needed to be able to use methicillin as a growth factor at concentrations of $5 \mu \mathrm{g} / \mathrm{ml}$ or less.

\section{Benzyl penicillin-resistant strain}

The method was identical to that used for isolating methicillin-dependent organisms, except that benzyl penicillin replaced methicillin. Earlier attempts to develop penicillin 
Table I. Inhibitory concentrations of methicillin and benzyl penicillin for $P$. cerevisiae $808 \mathrm{I}$ and substrains

\begin{tabular}{|c|c|c|}
\hline & \multicolumn{2}{|c|}{$\begin{array}{l}\text { Inhibitory concentration } \\
\qquad(\mu \mathrm{g} / \mathrm{ml})^{*}\end{array}$} \\
\hline Strain & Methicillin & $\begin{array}{c}\text { Benzyl } \\
\text { penicillin }\end{array}$ \\
\hline $808 \mathrm{I}$ & 10 & $1 \cdot 0$ \\
\hline CRD & 500 & $1.0 t$ \\
\hline MRD & 400 & 2.0† \\
\hline CR & 300 & 1.5 \\
\hline met $^{\mathrm{Rs}}$ & 75 & $2 \cdot 0$ \\
\hline $\operatorname{met}^{\mathrm{Rb} 1}$ & 300 & $1 \cdot 0$ \\
\hline Met $^{\mathrm{Rb} 2}$ & 300 & $2 \cdot 0$ \\
\hline Pen $^{\mathrm{R}}$ & 300 & $6 \cdot 0$ \\
\hline
\end{tabular}

* Maximum concentrations in which growth occurred after 3 days.

$\dagger$ Determined with methicillin $(50 \mu \mathrm{g} / \mathrm{ml})$ in the medium.

resistance in this way had been unsuccessful (White, 1968a) but no special difficulty was found in the present experiments. Resistance increased by small steps during passages $I$ to 23, from a maximum tolerated dose of $\mathrm{I} \mu \mathrm{g} / \mathrm{ml}$ up to $8 \mu \mathrm{g} / \mathrm{ml}$. No further increase in resistance occurred; indeed, after passage $3 \mathrm{I}$ only a 6-fold gain in resistance had been achieved. Organisms from this culture were designated 808I Pen $^{\mathrm{R}}$. At no stage did growth appear sooner when penicillin was present in the medium than in its absence. Growth without benzyl penicillin was almost always faster, and the final turbidity attained was often greater in drug-free medium. Whether Pen $^{\mathrm{R}}$ reverts to sensitivity, or whether the organisms lyse in the presence of higher concentrations of penicillin, has not been established. No attempts were made to isolate benzyl penicillin-dependent colonies by replica-plating.

\section{Properties of the parent and substrains compared}

Resistance to methicillin and benzyl penicillin. The inhibitory concentrations of benzyl penicillin and methicillin were determined for each strain (Table I). Large increases in methicillin resistance did not lead to comparable increases in resistance to benzyl penicillin, although the benzyl penicillin-resistant strain $808 \mathrm{I}$ Pen $^{\mathrm{R}}$ showed a I5- to 30 -fold increase (depending on the period of incubation) in methicillin resistance. The concentration of methicillin $(50 \mu \mathrm{g} / \mathrm{ml})$ added to the medium for estimation of the benzyl penicillin resistance of CRD and MRD was the highest that could be used without decreasing the resistance to benzyl penicillin. Strain CR, although no longer dependent on methicillin, still showed resistance to this antibiotic.

Thymidine requirement. White (1968a) found that neither parent nor CRD organisms grew in medium SD if leucovorin were omitted, even if pteroylglutamate (and methicillin) were added. However, the parent strain could grow if leucovorin was replaced by thymidine $(0 \cdot 1 \mathrm{mg} / \mathrm{l})$, though to only one-third of the final turbidity achieved with leucovorin. Strain CRD did not grow in such medium (plus methicillin), even after incubation for $120 \mathrm{~h}$.

To help determine whether this difference was in any way related to the biochemical mechanism of dependence on methicillin, growth of the newly-developed strains was examined on solid medium, to assess whether ability to grow was a property of the whole 


\section{Table 2. Vitamin requirements of $P$. cerevisiae 808I and substrains}

Organisms were harvested from medium SD (plus methicillin if needed for growth), washed in water and diluted to an estimated colorimeter reading of 0.002 (about $0.6 \mu \mathrm{g}$ dry wt organisms $/ \mathrm{ml}$ ). These suspensions $(0.1 \mathrm{ml})$ were used to inoculate $4.9 \mathrm{ml}$ portions of medium SD from which the vitamins were omitted singly.

Strain

\begin{tabular}{|c|c|c|c|c|c|c|c|}
\hline Vitạmin omitted & $808 \mathrm{I}$ & $\mathrm{CRD}^{*}$ & MRD*§ & CR & $\mathrm{Met}^{\mathrm{Ra}}$ & Met $^{\mathrm{Rb} 1}$ & $\mathrm{Met}^{\mathrm{Rb} 2}$ \\
\hline Leucovorin & - & - & - & - & - & - & - \\
\hline $\begin{array}{l}\text { Leucovorin } \\
\text { (replaced by thym }\end{array}$ & $\begin{array}{c}+++ \\
\text { idine) }\end{array}$ & - & +++ & ++ & + & - & +++ \\
\hline Pantothenate & $++t$ & - & - & - & - & ND & ND \\
\hline Biotin & \pm & - & \pm & ND & \pm & ND & ND \\
\hline Nicotinic acid & \pm & - & - & ND & - & ND & ND \\
\hline Riboflavin & +++ & ++ & +++ & ND & $++t$ & ND & ND \\
\hline Thiamin & +++ & ++ & $+t+$ & ND & $+t+$ & ND & ND \\
\hline $\mathbf{B}_{6} \uparrow$ & +++ & $+t$ & +++ & ND & $++t$ & ND & Nì \\
\hline
\end{tabular}

+++ , Heavy growth; -, no growth; ND, not determined.

* Methicillin $(50 \mu \mathrm{g} / \mathrm{ml})$ added.

$\dagger$ Pyridoxin + pyridoxal + pyridoxamine all omitted together.

\& These liquid cultures of strain MRD would have contained revertants to drug independence, even though methicillin was present. Consequently, the ability to grow in the absence of a given vitamin is not necessarily a property of strain MRD. A separate experiment (see text) confirmed that strain MRD could grow with thymidine in place of leucovorin.

population or of only a few colonies. Strains MRD, 808I Met ${ }^{\mathrm{Bb} 2}$ and CR were all able to grow with thymidine in place of leucovorin, whereas $808 \mathrm{I}$ Met $^{\mathrm{Ra}}$ grew only poorly and 808I $\mathrm{Met}^{\mathrm{Rb} 1}$ did not grow with thymidine. Thus, the inability to grow on a medium in which leucovorin is replaced by thymidine is not a property that is essentially linked to methicillin dependence.

Vitamin requirements. Strains $808 \mathrm{I}$ (parent), CRD, MRD, CR and 8081 met ${ }^{\text {ta }}$ were investigated (Table 2). All the strains that were resistant to methicillin showed a requirement for pantothenate, which was not required by the parent. None of the resistant strains grew if medium without pantothenate was supplemented with $\beta$-alanine $(\mathrm{I} \mu \mathrm{g} / \mathrm{ml})$ plus pantolactone ( $\mu \mathrm{g} / \mathrm{ml}$ ). Medium SD (in which all the substrains were isolated) contained sodium pantothenate (I mg/l).

Amino acid requirements. The parent strain grew in the chemically defined medium that was produced by replacing the acid-hydrolysed casein in medium SD by amino acids. Strain CRD required methicillin (about $20 \mu \mathrm{g} / \mathrm{ml}$ was optimal) for growth in this medium, but only light turbidity was produced even after incubation for 2 days or longer. Strain $808 \mathrm{I}$ grew in the absence of aspartic acid or asparagine (but not of both) or of lysine; omission of any other amino acid prevented growth. Strain CRD did not grow when any single amino acid was omitted.

Acetate requirement. Strain CRD grew without methicillin in medium SD containing decreased concentrations of sodium acetate (White, 1968a). The inhibitory effect of $2 \%$ $(\mathrm{w} / \mathrm{v})$ sodium acetate might have been a consequence of autoclaving, because the medium with acetate became browner on autoclaving than did medium without acetate. Medium SD lacking acetate was therefore made, without any heating during its preparation, and was sterilized by filtering and dispensed into sterile tubes. Various amounts of sodium acetate were added, as a solution adjusted to $\mathrm{pH} 6.5$ and sterilized by filtering. Tubes were inoculated with 808I or CRD (overnight cultures diluted to the equivalent of a colorimeter reading of 0.002). Uninoculated medium was also incubated, with and without methicillin, to check that none of the solutions were contaminated. 


\title{
Table 3. Ability of $P$. cerevisiae 8081 and methicillin-resistant substrains to
} grow in the absence of acetate

\begin{abstract}
Organisms were grown overnight in medium SD, plus methicillin $(50 \mu \mathrm{g} / \mathrm{ml})$, for all strains except the parent. Inocula $(0.1 \mathrm{ml})$ of about 1000 colony-forming units from each culture were plated on medium SD plus thioglycollate but lacking sodium acetate. Plates were incubated at $37^{\circ} \mathrm{C}$ for for $72 \mathrm{~h}$. The number of colonies (where these appeared) was similar in all cases.
\end{abstract}

$$
\begin{aligned}
& \text { Growth on medium } \\
& \text { without acetate } \\
& \text { Strain } \overbrace{- \text { Methicillin }}^{+ \text {Methicillin }} \\
& \begin{array}{ccc}
8081 & +++ & - \\
\text { CRD } & - & - \\
\text { CR } & \pm & - \\
\text { MRD } & - & +++ \\
\operatorname{Met}^{\mathrm{Ra}} & ++ & ++ \\
\operatorname{Met}^{\mathrm{RL1}} & +++ & +++ \\
\operatorname{Met}^{\mathrm{Rb2}} & +++ & +++
\end{array} \\
& +++ \text {, Large colonies; } \pm \text {, very small colonies; }- \text {, no growth. }
\end{aligned}
$$

The inhibitory effect of acetate was clearly not a result of autoclaving. Strain CRD was inhibited by $2 \%(w / v)$ sodium acetate unless methicillin was present, and $4 \%$ was inhibitory even when the drug was added. Growth without methicillin occurred with 0.1 to I $\%$ acetate; $0.4 \%$ was optimal. The parent strain was not inhibited by $4 \%(w / v)$ acetate and could grow, to a limited extent, in the absence of acetate. Addition of lipoic acid in the range $0 . \mathrm{I}$ to $100 \mu \mathrm{g} / \mathrm{l}$ did not improve the growth of either strain in filtered medium without acetate. The newly-isolated strains were tested on solid medium SD without acetate (Table 3). All strains, except CRD or CR, grew without acetate. Thus, the requirement for acetate shown by strain CRD is not a property that is necessarily linked to methicillindependence.

Fermentation of glucose. The concentration of glucose in medium SD could be decreased from 25 to $10 \mathrm{~g} / \mathrm{l}$ before there was a decrease in the final yield of the parent strain. Strain CRD grew less heavily than the parent strain in medium SD (plus $100 \mu \mathrm{g}$ methicillin $/ \mathrm{ml}$ ) and there was little change in the yield of bacteria until the concentration of glucose was less than $5 \mathrm{~g} / \mathrm{l}$. With none of the altered concentrations of glucose was there growth of CRD in the absence of methicillin. Neither strain grew in medium SD without glucose, whether or not methicillin was present.

Washed suspensions of organisms of strains $808 \mathrm{I}$ and CRD fermented glucose in the absence of methicillin at similar rates. From $5 \mu \mathrm{mol}$ glucose, $10 \mu \mathrm{mol} \mathrm{CO}$ (all due to acid production) was evolved in bicarbonate buffer. The presence of methicillin did not alter the rate or amount of gas evolution with either strain. No gas was evolved when glucose was fermented in phosphate buffer, though all the glucose disappeared and lactate was formed. Total lactic acid production was $12 \mu \mathrm{mol}$ from $5 \mu \mathrm{mol}$ glucose, and $2 \mu \mathrm{mol}$ when no glucose was added to the suspended bacteria. With both strains, most of the lactate (about $75 \%$ ) was L-isomer (cf. Gordon \& Doelle, 1975). 


\section{DISCUSSION}

The first object of this study was to see whether a second methicillin-dependent substrain of $P$. cerevisiae $808 \mathrm{I}$ could be isolated. Such a strain was obtained at the first attempt, and so the earlier isolation of a methicillin-dependent organism was not a unique unrepeatable event. However, the new dependent strain (MRD) was isolated less readily than strain CRD (White, 1968a); replica-plating was needed to make a final selection of MRD organisms. Strain MRD was distinct from CRD: acetate was not required for growth of MRD, and the rate of reversion of MRD to drug independence was very much higher. A possible interpretation of these findings is that strain MRD has become methicillin-dependent as a consequence of a single unstable mutation, whereas CRD has undergone either a different and more stable mutation, or else has suffered a second mutation that has stabilized the drug dependence. When strain CRD reverted to drug independence it maintained its methicillin resistance and also its nutritional requirement for acetate, so that CRD seems to differ from the parent strain by at least two (and probably more) mutational steps.

Resistance to methicillin increased stepwise during experiments with a mutagen (NTG). The first step gave resistance to $75 \mu \mathrm{g}$ methicillin $/ \mathrm{ml}$, the second to $150 \mu \mathrm{g} / \mathrm{ml}$; presumably at least one more step would be needed to give resistance to $400 \mu \mathrm{g} / \mathrm{ml}$, as is found in MRD and CRD. This level of resistance to methicillin can be achieved without drug dependence being a necessary accompaniment (e.g. strain CR). Whether drug dependence might emerge without simultaneous gain of resistance is doubtful. Six attempts to isolate a methicillindependent organism that was not resistant were unsuccessful. Although methicillin-dependent organisms (of strain CRD) might have some selective advantage over methicillin-resistant but independent organisms (White, 1968a), this advantage may be so slight that dependent organisms might make up an apppreciable part of a population only after a large number of transfers in the presence of the drug. Possibly methicillin-dependent organisms need a higher external concentration of the drug for growth than can be tolerated by a nonresistant organism. Strain CRD grew poorly with less than $40 \mu \mathrm{g}$ methicillin $/ \mathrm{ml}$ and about $100 \mu \mathrm{g} / \mathrm{ml}$ was optimal. Other penicillins (e.g. benzyl penicillin, ampicillin) had only slight growth factor activity at concentrations that did not inhibit CRD, which was not resistant to these compounds (White, 1968a).

The lack of cross-resistance to benzyl penicillin is a striking feature of all the methicillinresistant strains. The strain $\left(8081\right.$ Pen $\left.^{\mathrm{R}}\right)$ resistant to benzyl penicillin, however, had developed 15- to 30-fold resistance to methicillin as well as 6-fold resistance to benzyl penicillin. A possible interpretation of these findings is that resistance to methicillin might have developed by a mechanism (e.g. a specific diminished uptake) that did not confer resistance to other penicillins, while resistance to benzyl penicillin, which was more difficult to develop, arose by a different process that led to resistance against other derivatives of 6-aminopenicillanic acid.

No clear patterns emerged from the comparisons of the nutrition of $P$. cerevisiae 808I and the methicillin-resistant substrains. The only common feature shown by all the resistant strains (whether methicillin-dependent or not) was a nutritional requirement for pantothenate, which was not needed by the parent strain. Pantothenate is a precursor of CoA, and this cofactor participates in the metabolism of acetate, which is disturbed in strain CRD (White, $1968 a$ ). Unlike the parent strain, CRD required acetate for growth yet was inhibited by concentrations of acetate higher than $I \%(w / v)$ unless methicillin were present. The need for acetate was not shown by strain MRD but was shown by methicillin-independent revertants of CRD, so that this property is not an inevitable consequence of methicillin 
dependence. Whether acetate is toxic to strain MRD in the absence of methicillin has not been established.

The ability of strain 8081 to grow to moderate turbidity in the absence of lysine was unexpected, though mutants of other lactic acid bacteria have been found that do not require this amino acid (Vogel, Thompson \& Shockman, 1970; Morishita et al. 1974). Strain CRD did not grow without lysine. This difference may be unrelated to drug dependence or it might reflect a greater requirement for lysine, which would be needed to synthesize the increased amount of peptidoglycan found in the wall of strain CRD (White, $1968 b$ ).

A scholarship from the Medical Research Council was held by D.W. during this work. Miss Lorna B. Young and Miss Gwen Lidlow gave valuable technical assistance in certain experiments.

\section{REFERENCES}

BARKER, S. B. (1957). Preparation and colorimetric determination of lactic acid. Methods in Enzymology 3, $24 I-246$.

BERGMEYER, H.-U. \& BERNT, E. (1965). Determination with glucose oxidase and peroxidase. In Methods of Enzymatic Analysis, pp. 123-1 30. Edited by H.-U. Bergmeyer. New York \& London: Academic Press.

Gordon, G. L. \& Doelle, H. W. (1975). Production of racemic lactic acid in Pediococcus cerevisiae cultures by two lactate dehydrogenases. Journal of Bacteriology I21, 600-607.

HohorsT, H.-J. (1965). L-(+)-Lactate. Determination with lactic dehydrogenase and DPN. In Methods of Enzymatic Analysis, pp. 266-270. Edited by H.-U. Bergmeyer. New York \& London: Academic Press.

Lederberg, J. \& LeDerberG, E. M. (1952). Replica plating and indirect selection of bacterial mutants. Journal of Bacteriology 63, 399-406.

Markov, K. I. \& SaEv, G. K. (1956). Penicillin und Thiamin als Wachstumsfaktoren für Staphylokokken. Zentralblatt für Bakteriologie, Parasitenkunde, Infektionskrankheiten und Hygiene (Abteilung I) 167, 216-223.

Markov, K. I. \& SAEv, G. K. (1957). Das Penicillin - ein spezifischer Wachstumsfaktor für Staphylokokken. Zentralblatt für Bakteriologie, Parasitenkunde, Infektionskrankheiten und Hygiene (Abteilung I) 168, 303-312.

Morishita, T., Fukada, T., Shirota, M. \& Yura, T. (1974). Genetic basis of nutritional requirements in Lactobacillus casei. Journal of Bacteriology 120, $1078-1084$.

Sauberuich, H. E. \& BaumanN, C. A. (1948). A factor required for the growth of Leuconostoc citrovorum. Journal of Biological Chemistry 176, 165-173.

Umbreit, W. W., BURris, R. H. \& Stauffer, J. F. (1964). Manometric Techniques, 4th edn. Minneapolis: Burgess.

Vogel, H. J., Thompson, J. S. \& Shockman, G. D. (1970). Characteristic metabolic patterns of prokaryotes and eukaryotes. Symposia of the Society for General Microbiology 20, 107-1 19.

WHrTE, P. J. (1968a). A substrain of Pediococcus cerevisiae which requires methicillin for growth. Journal of General Microbiology 50, 85-105.

WHrTE, P. J. (1968b). A comparison of the cell walls of Pediococcus cerevisiae and of a substrain that requires methicillin for growth. Journal of General Microbiology 50, 107-1 20.

WhITE, P. J. \& Nichol, C. A. (I963). Effects of uracil and thymidine on the development of resistance to 5-fluorouracil in Pediococcus cerevisiae. Journal of Bacteriology 85, 97-105.

WIDDowson, D. \& WHITE, P. J. (1971). New methicillin-resistant and dependent substrains of Pediococcus cerevisiae and their uptake of benzyl penicillin. Journal of General Microbiology 66, ii.

WILKInson, B. J. \& WHITE, P. J. (1973). The effect of antibiotics on synthesis of mucopeptide and teichoic acid by Pediococcus cerevisiae and by a substrain that requires methicillin for growth. Journal of General Microbiology 79, 195-204. 